\title{
Properties of Portland-Composite Cements with metakaolin: Commercial and manufactured by Thermal Activation of Serbian Kaolin Clay
}

\author{
A. Mitrovic ${ }^{1}$ and D. Nikolic ${ }^{2}$
}

${ }^{1}$ Institute for testing of materials, Management, Belgrade, Serbia

${ }^{2}$ Institute for testing of materials, Department for materials, Belgrade, Serbia

\begin{abstract}
Portland-composite cements (CEM II) were prepared with addition of 5 to $35 \%$ of metakaolin (MK), manufactured by thermal activation/calcination of Serbian kaolin clay, and commercial matakaolin (CMK). Performance of the composite cements was evaluated, through the setting time (initial and final), compressive strengths (for ages 2, 7, 28, 90 and 180 days) and soundness, and compared with control cement (Portland cement - CEM I). Setting time (initial and final) is accelerated in Portlandcomposite cements, for both metakaolins used. The acceleration is higher in cement with addition of commercial metakaolin. Lower compressive strength is obtained after 2 days of curing for all Portland-composite cements in comparison with control cement, since pozzolanic reaction still did not show its effect. After 7 days, pozzolanic reaction show its effect, manifested as compressive strength increase of Portland-composite cements with addition of up to $35 \%$ of CMK, and $25 \%$ in the case of cements with MK. After 28 days compressive strength was higher than that for control cement for cements prepared with addition of CMK, and with addition of up to $25 \%$ MK. After 90 days increased compressive strength was noticed with addition of $10-20 \%$ of CMK, and with 10 and $15 \%$ of MK, while after 180 days addition of both metakaolins influences compressive strength decrease. The results of the soundness, $0.5 \mathrm{~mm}$ for CEM I, and $1.0 \mathrm{~mm}$ in most Portland-composite cements indicate soundness increase with addition of metakaolins. Generally, better performance of Portland-composite cements was obtained with addition of commercial metakaolin, which may be attributed to the differences in the pozzolanic activity of the applied metakaolins, 20.5 MPa and 14.9 MPa for CMK and $\mathrm{MK}$, respectively. By our previous findings pozzolanic activity of the thermally activated clay may be increased by subsequent milling of the metakaolin manufactured by thermal activation process.
\end{abstract}




\section{INTRODUCTION}

In Serbia, in three cement plants, the annual production of Portland-composite cement (CEM II) with blast furnace slag, coal ash and natural pozzolana is approximately 2.5 million tons. As cement industry in the world, Serbian cement industry is facing challenges in terms of increasing durability, improving performance and sustainable production.

The use of pozzolanic materials for partial replacement of clinker or Portland cement in Portlandcomposite cements and concrete mixtures has become almost unavoidable owing to their beneficial effects on the ultimate compressive strength, permeability and chemical durability, as well as by the economic and ecologic advantage of their use [1]( R.Siddique, 2009).

limestone are used. The shares of allowances range from 5 to $35 \%$ by mass, depending on market requirements and product assortment.

Since mid-1990, a highly reactive metakaolin (HRM), a pozzolanic addition for cement and concrete, is produces in several factories around the world by thermal activation/calcination of previously refined kaolin clay with a high content of kaolinite. Its application in the regular concrete is limited because of the relatively high cost of production. In previous works [2,3](B.Ilić, 2010, A.Mitrović, 2009) authors presented the results of preparing matekaolin by thermal activation of several kaolinite clays. The proces depends on the raw clays properties, as weel as proces parameters. The produced metakaolins, in comparation with commercial metakaolin, posses aproximatelly the some pozollanic activity determined either by Chapelle method or by standard [4](SRPS B.C1.018:2001), as well as mean diameter. First attempts on making metakaolin encouraged authors to continue their researches.

Although manufactured metakaolin posses high pozzolanic activity, verification of his performance in cement-based systems is necessary. In this paper we present the first results on performance of the Portland-composite cement with addition of $5-35 \%$ by mass of metakaolin manufactured by thermal activation of Serbian kaolin clay.

\section{EXPERIMENTAL}

\subsection{Starting materials}

For the preparation of the Portland-composite cements Lafarž BFC PC (CEM I 42,5R), metakaolin (MK) obtained by thermal activation/calcination of "Garaši” kaolin clay and commercial metakaolin (CMK) were used. Chemical composition and physical properties of the starting materials are shown in table 1 .and 2.

Table 1. Chemical composition and physical properties of the Portland cement (CEM I 42,5R)

\begin{tabular}{|c|c|c|c|}
\hline \multicolumn{4}{|c|}{ Chemical composition ( $\%$ by mass) } \\
\hline $\mathrm{SiO}_{2}$ & 20,36 & Insoluble residue in $\mathrm{HCl} / \mathrm{Na}_{2} \mathrm{CO}_{3}$ & 1,11 \\
\hline $\mathrm{Al}_{2} \mathrm{O}_{3}$ & 5,83 & Insoluble residue in $\mathrm{HCl} / \mathrm{KOH}$ & 0,62 \\
\hline $\mathrm{Fe}_{2} \mathrm{O}_{3}$ & 2,96 & $\mathrm{CO}_{2}$ & 1,04 \\
\hline $\mathrm{CaO}$ & 62,36 & $\mathrm{CaO}$, Free & 0,43 \\
\hline $\mathrm{MgO}$ & 1,32 & & \\
\hline $\mathrm{SO}_{3}$ & 2,80 & & \\
\hline $\mathrm{Na}_{2} \mathrm{O}$ & 0,15 & \multicolumn{2}{|c|}{ Physical properties } \\
\hline $\mathrm{K}_{2} \mathrm{O}$ & 0,79 & Residue on siev $0.09 \mathrm{~mm} \mathrm{( \% )}$ & 0,3 \\
\hline $\mathrm{MnO}$ & 0,127 & Sp (Blaine) $\left(\mathrm{cm}^{2} / \mathrm{g}\right)$ & 4430 \\
\hline LOI & 3,00 & $\gamma_{\mathrm{s}}(\mathrm{g} / \mathrm{cm} 3)$ & 3,10 \\
\hline Sum: & 99,70 & & \\
\hline
\end{tabular}


Table 2. Chemical composition and physical properties of the metakaolin (CMK) and (MK)

\begin{tabular}{|c|c|c|c|c|c|}
\hline \multicolumn{3}{|c|}{ Chemical composition (\% by mass) } & \multicolumn{3}{|c|}{ Physical properties } \\
\hline & CMK & MK & & CMK & MK \\
\hline $\mathrm{SiO}_{2}$ & 55.00 & 63.91 & $\gamma_{\mathrm{s}}\left(\mathrm{g} / \mathrm{cm}^{3}\right)$ & 2.61 & 2.42 \\
\hline $\mathrm{Al}_{2} \mathrm{O}_{3}$ & 40.00 & 28.71 & Sp (Blaine) $\left(\mathrm{cm}^{2} / \mathrm{g}\right)$ & - & 7400 \\
\hline $\mathrm{Fe}_{2} \mathrm{O}_{3}$ & 1.40 & 2.37 & \multirow{2}{*}{$\begin{array}{l}\text { Pozzolanic activity } \\
\left(\mathrm{gCa}(\mathrm{OH})_{2} / \mathrm{g} \mathrm{MK}\right)\end{array}$} & \multirow{2}{*}{0.78} & \multirow{2}{*}{0.60} \\
\hline $\mathrm{TiO}_{2}$ & 1.50 & - & & & \\
\hline $\mathrm{CaO}+\mathrm{MgO}$ & 0.30 & 1.03 & \multirow{4}{*}{$\begin{array}{l}\text { Pozzolanic activity } \\
\qquad(\mathrm{MPa})\end{array}$} & \multirow{4}{*}{20.5} & \multirow{4}{*}{14.9} \\
\hline $\mathrm{Na}_{2} \mathrm{O}+\mathrm{K}_{2} \mathrm{O}$ & 0.80 & 1.72 & & & \\
\hline LOI & 1.00 & 1.02 & & & \\
\hline Sum: & 100.00 & 98.81 & & & \\
\hline
\end{tabular}

\subsection{Applied experimental methods}

The chemical composition of cement is determined by standard methods [5](SRPS EN 196-2), while chemical composition of metakaolin is determined by silicate analysis.

Cement physical properties, such as standard consistency, setting time, specific gravity were determined according to the standards [6,7](SRPS EN 196-3, SRPS B.C8.023), compressive strengths according to the standard [8]( SRPS EN 196-1) and soundness according to [6].

Pozzolanic activity is determined according to the standard [4](SRPS B.C1.018:2001).

\subsection{Preparation of the cement with addition of metakaolin}

In order to determine the characteristics of Portland-composite cement with the addition of metakaolin cement samples were prepared with the metakaolin addition of 5, 10, 15, 20, 25, 30 and $35 \%$ by mass.

To test the compressive strength after 2, 7, 28, 90 and 180 days mortar mixes were prepared according to the standard [8]( SRPS EN 196-1) with water-cement factor (w/c) 0.5; and the ratio of binder-sand $=1: 3$.

\section{RESULTS AND DISSCUSION}

The influence of addition of metakaolin, in quantities 5 to $35 \%$ by mass, to the Portland cement were determined through the examination of setting times, compressive strengths and soundness.

\subsection{Setting time}

The influence of the metakaolin addition on setting time is shown in table 3.

Table 3. The influence of metakaolin on the setting time of the Portland-composite cements.

\begin{tabular}{|c|c|c|c|c|}
\hline Sample & $\begin{array}{c}\text { Metakaolin } \\
(\boldsymbol{\%} \text { by mass })\end{array}$ & $\begin{array}{c}\text { Standard consistency } \\
(\boldsymbol{\%})\end{array}$ & \multicolumn{2}{|c|}{$\begin{array}{c}\text { Setting time (min) } \\
\text { Initial }\end{array}$} \\
\hline CEM I & - & 30.0 & 260 & 320 \\
\hline CMK 5 & 5 & 30.6 & 240 & 300 \\
\hline CMK 10 & 10 & 31.2 & 185 & 240 \\
\hline CMK 15 & 15 & 32.8 & 185 & 240 \\
\hline CMK 20 & 20 & 34.6 & 185 & 245 \\
\hline CMK 25 & 25 & 36.6 & 185 & 235 \\
\hline CMK 30 & 30 & 38.4 & 165 & 215 \\
\hline CMK 35 & 35 & 40.6 & 165 & 215 \\
\hline
\end{tabular}




\begin{tabular}{|c|c|c|c|c|}
\hline MK 5 & 5 & 30.4 & 220 & 280 \\
\hline MK 10 & 10 & 30.8 & 220 & 280 \\
\hline MK 15 & 15 & 31.8 & 200 & 250 \\
\hline MK 20 & 20 & 34.2 & 210 & 250 \\
\hline MK 25 & 25 & 35.2 & 210 & 270 \\
\hline MK 30 & 30 & 36.4 & 190 & 240 \\
\hline MK 35 & 35 & 38.0 & 180 & 230 \\
\hline
\end{tabular}

The results indicate that Portland-composite cements requires a larger amount of water to achieve a standard consistency of the control Portland cement (CEM I 42,5R), which is in agreement with results published by other authors [9, 10](E.Badogiannis, 2005, G.Batis, 2005). They concluded that the composite cement demand more water than the relatively pure cement and that this phenomenon is attributed to the high fineness of metakaolin.

All blended cements showed slow setting time (initial and final) than that of control cement, in other words they accelerate initial and final setting time. The higher acceleration occurs by adding commercial metakaolin. The results are in line with the results of Justice [11](JM.Justice, 2005), which indicate that addition metakaolin accelerates setting time, and that setting time of Portland composite cement depends on the amount of added metakaolin.

\subsection{Compresive strengts}

Scientific literature clearly shows that, owing to its pozzolanic properties, metakaolin addition to portland cement have positive influence on the compressive strengths. In paper [12](M.Arikan, 2009) reported that the application of thermally activated kaolin provides a $15 \%$ improvement of the compressive strength of cement.

The influence of the metakaolin addition on compressive strength of Portland-composite cements is shown in fig. 1.

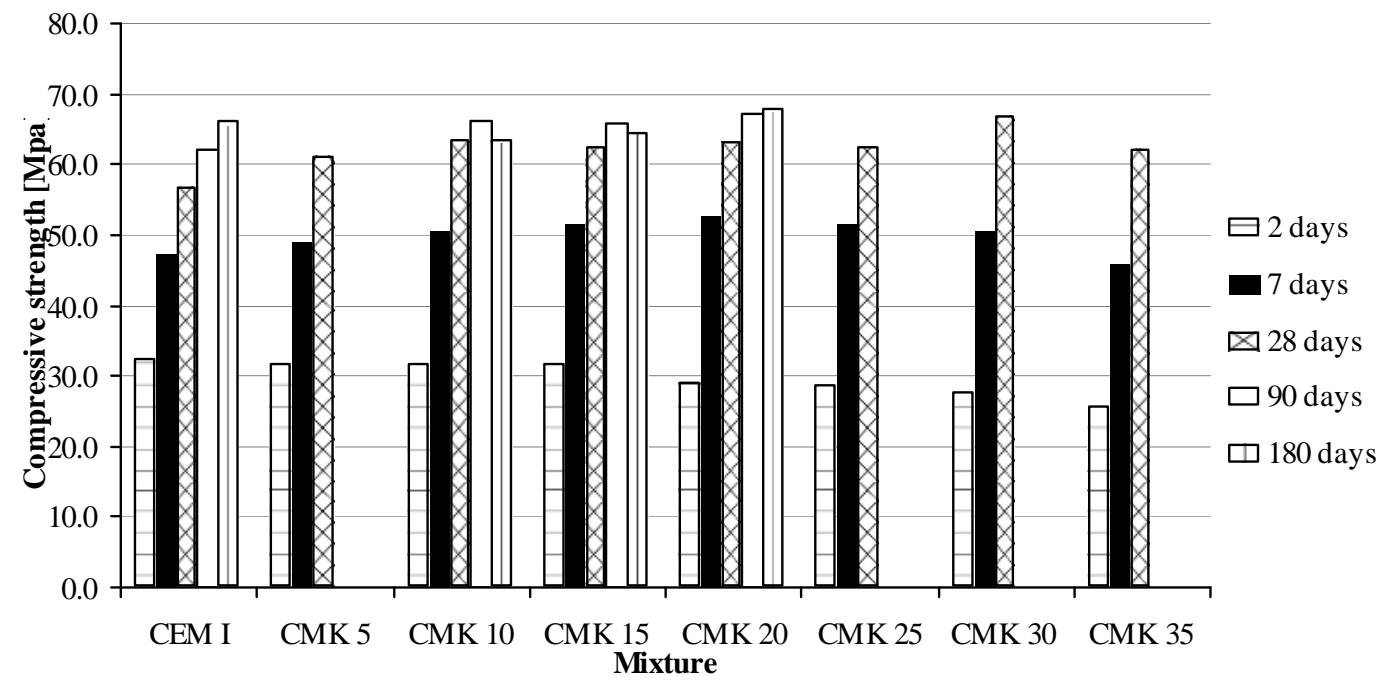




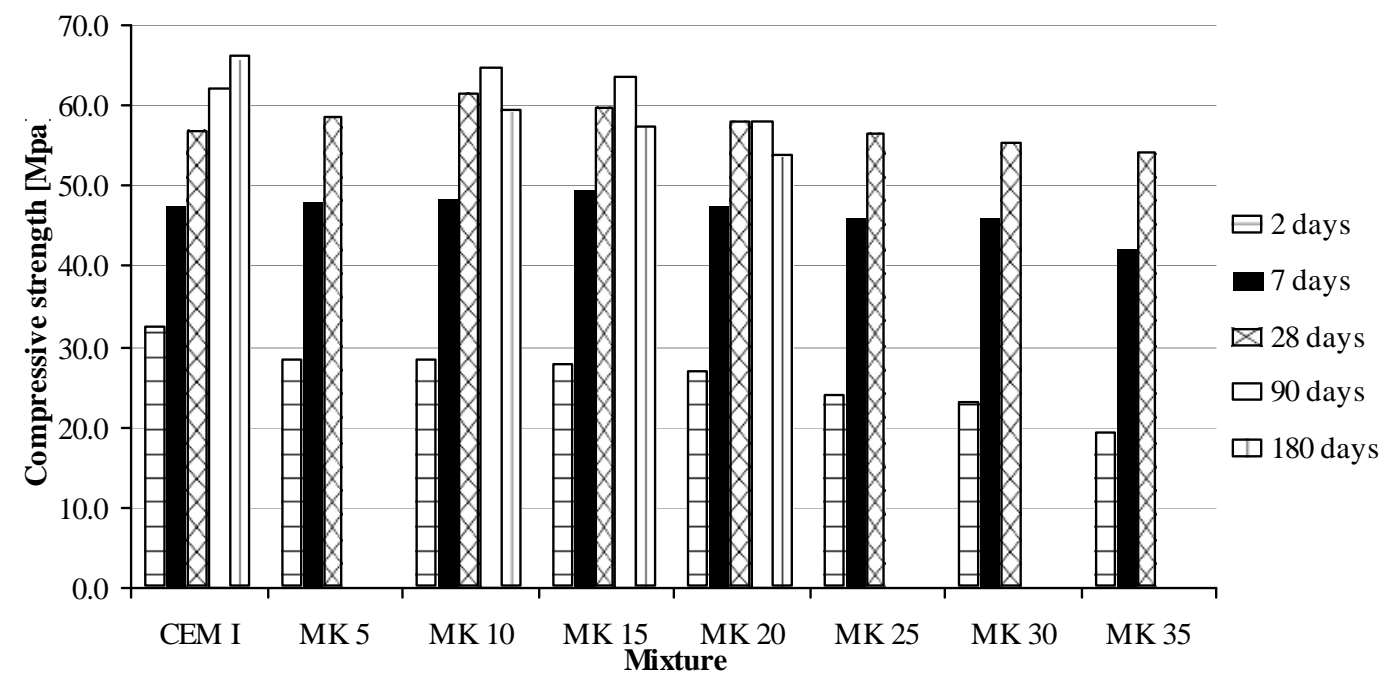

Fig. 1 Compressive strengths for various quantities of added metakaolin;

(a) commercial metakaolin CMK, and (b) metakolin produced by thermal activation MK.

After 2 days of curing all composite cements shows lower compressive strength in comparison with control cement. This might be explained by the fact that pozzolanic reaction still did not show its effect. The compressive strength of cements with MK is lower than those obtained with commercial MK, particular with addition of more than $25 \%$ of MK.

After 7 days composite cements with CMK, with exception of cement with 35\%, has higher compressive strength than control cement. The increase is approximately $10 \%$ with addition of 15 $25 \%$ of CMK. Composite cements with MK up to $25 \%$ have nearly the same compressive strength as control cement.

After 28 days all composite cements with CMK showed higher compressive strength than control cement. Addition of MK up to $25 \%$ shows positive effect on strength, but this effect is lower than that obtained with commercial MK.

The influence of prolonged curing, 90 and 180 days, were investigated on the composite cements with addition of 10,15 and $20 \%$ of metakaolin, as literature suggests that those quantities gives the best results. After 90 days addition of $10-20 \%$ of CMK shows increase in strength, as well as cements with 10 and $15 \%$ of MK.

After 180 days the increase was noticed only with addition of $20 \%$ of CMK.

Lower values for compressive strength in Portland-Composite cement with MK might be explained throught the differences in pozzolanic activity and specific surface of the applied metakaolins. Commercial metakaolin have pozzolanic activity of $20.5 \mathrm{MPa}$ or $0.78 \mathrm{gCa}(\mathrm{OH}) 2 / \mathrm{gMK}$ (Chapelle method), while metakaolin obtained by thermal activation have significantly lower values, $14.9 \mathrm{MPa}$ or $0,60 \mathrm{gCa}(\mathrm{OH}) 2 / \mathrm{gMK}$. Also, the specific surface couldn't be measured by Blaine, indicating higher values than those obtained for MK. We expect that pozzolanic activity of thermally activated 
clay could be increased by subsequent grinding of MK, and thus to obtain compressive strength comparable with cement prepared with commercial metakaolin.

The results are consistent with the results obtained by other authors [13,14](J.Bensted, 2002, D.Vu, 2001) where data shows reduction of early compressive strength with addition of metakaolin. In papers [13,15](J.Bensted, 2002, J.Cabrera, 2001) authors have concluded that the optimal amounts of addition metakaolin are $10 \%$ and $15 \%$.

Our investigations show that the optimal amount of addition of CMK is $20 \%$, and $5-10 \%$ of MK.

\section{3. Soundness}

The influence of CMK and MK on the soundness is shown in table 4. The mortar soundness (expansion) of $0.5 \mathrm{~mm}$ for CEM I, and in most Portland-composite cements $1.0 \mathrm{~mm}$ indicate shrinkage increase in composite cement. Increase in soundness with addition of metakaolin can be explained by the relative increase in volume of reaction products.

Table 4. The influence of CMK and MK on the soundness

\begin{tabular}{|c|c|c|}
\hline $\begin{array}{c}\text { Metakaolin } \\
\text { (\% by mass) }\end{array}$ & \multicolumn{2}{|c|}{$\begin{array}{c}\text { Soundness, Le Chatelier, } \mathbf{~ m m} \\
\text { CMK }\end{array}$} \\
\hline- & 0.5 & 0.5 \\
\hline 5 & 1.0 & 1.0 \\
\hline 10 & 1.0 & 1.0 \\
\hline 15 & 0.5 & 1.0 \\
\hline 20 & 1.0 & 1.0 \\
\hline 25 & 1.0 & 1.0 \\
\hline 30 & 1.0 & 0.5 \\
\hline 35 & 1.0 & 1.0 \\
\hline
\end{tabular}

\section{CONCLUSION}

The results obtained in this study allow us to drown following conclusions:

- Portland-composite cements requires a larger amount of water to achieve a standard consistency of the control Portland cement,

- Addition of commercial metakaolin and metakaolin manufactured by thermal activation in a quantity $5-35 \%$ by mass accelerate initial and final setting time,

- Compressive strength after 2 days for both metakaolins is lower than that of control cement as pozzolanic reaction still did not show its effect,

- For 7, 28, and 90 days addition CMK up to 30\% increases compressive strength of composite cement,

- Increase in compressive strength for 7, 28, and 90 days was observed for addition, up to $15 \%$ of $\mathrm{MK}$,

- After 180 days only cement with $20 \%$ of CMK show compressive strength increase,

In most Portland-composite cements soundness is constant, $1 \mathrm{~mm}$ but higher than that in control cement.

The lower values for compressive strength of the composite cements prepared with addition of metakaolin produced by thermal activation of Serbian kaolinite clay were expected as metakaolin (MK) have lower pozzolanic activity and specific surface than commercial metakaolin (CMK). 


\section{INVACO2}

\section{Acknowledgements}

The authors are very grateful to the Serbian Ministry for science and technological development, which supported the present research (TR 36017).

\section{References}

1. Siddique, R. and Klaus, J. Influence of metakaolin on the properties of mortar and concrete: A review. Applied Clay Science, 43, 392-400.( 2009)

2. Ilić, B., Mitrović, A., Miličić, Lj. Thermal Treatment of Kaolin Clay to Obtaine Metakaoline, Hem.ind., 64 (4), 351-356.( 2010)

3. Mitrović, A., Komljenović, M., Ilić, B. Research of possibilities for use domestic kaolin clays for production of metakaolin, Hem.ind.,63 (2), 107-113.( 2009)

4. SRPS B.C1.018: Non - Metalic Mineral Raws Puzzolanic Materials - Costituents for Cement Prodaction Classification, technical conditions and test methods.( 2001)

5. SRPS EN 196-2: Methods of testing cement-Part 2:Chemical analysis of cement.( 2008)

6. SRPS EN 196-3: Methods of testing cement-Part 3:Determination of setting time and soundness. (2007)

7. SRPS B.C8.023: Cements. Methods of testing cements - phisical test.( 1997)

8. SRPS EN 196-1: Methods of testing cement-Part 1:Determination of strength.( 2008)

9. Badogiannis, E., Kakali, G., Dimopoulou, G., Chaniotakis, E., Tsivilis, S., Metakaolin as a main cement constituent: exploitation of poor Greek kaolins. Cem. Concr.Compos., 27(2), 197203.(2005)

10. Batis, G., Pantazopoulou, P., Tsivilis, S., Badogiannis, E., The effect of metakaolin on the corrosion behavior of cement mortars. Cem. Concr. Compos., 27(1), 125-130.( 2005)

11. Justice, JM., Evaluation of metakaolins for use as supplementary cementitious materials. A Thesis (MsS). The Academic Faculty, Georgia Institute of Technology, USA.( 2005)

12. Arikan, M., Sobolev, K., Ertu“n, T., Yeg־inobali, A., Turker, P., Properties of blended cements with thermally activated kaolin. Construction and Building Materials, 23, 62-70.( 2009)

13. Bensted, J., Barnes, P., Structure and Performance of Cements. 2nd ed. New York: Spon Press.(2002)

14. Vu, DD., Stroeven, P., Bui, VB., Strength and durability aspects of calcined kaolin-blended Portland cement mortar and concrete. Cem. Concr. Compos., 23(6), 471-478.(2001)

15. Cabrera, J., Rojas, M.F, Mechanism of hydration of the metakaolin-lime-water system. Cem. Concr. Res., 31(2), 177-182.(2001) 